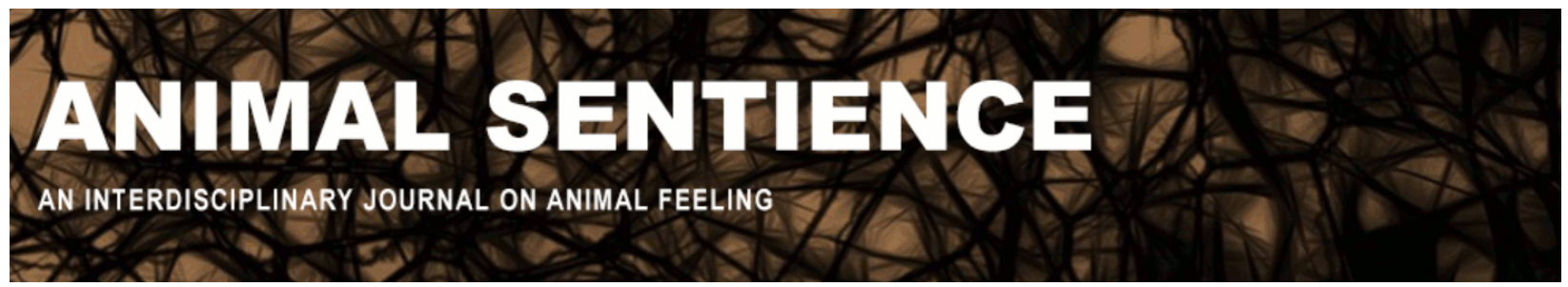

Marazziti, Donatella (2018) Only the human brain has the cognitive capacity for jealousy. Animal Sentience 22(19)

DOI: $10.51291 / 2377-7478.1357$

Date of submission: 2018-07-04

Date of acceptance: 2018-07-13

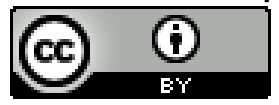

This article has appeared in the journal Animal

Sentience, a peer-reviewed journal on animal

cognition and feeling. It has been made open access,

free for all, by WellBeing International and deposited

in the WBI Studies Repository. For more information,

please contact

wbisr-info@wellbeingintl.org.

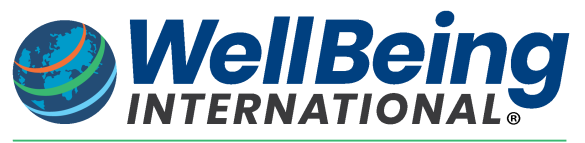

SOLUTIONS FOR PEOPLE, ANIMALS AND ENVIRONMENT 


\title{
Only the human brain has the cognitive capacity for jealousy
}

\author{
Commentary on Cook et al. on Dog Jealousy
}

\author{
Donatella Marazziti \\ Dipartimento di Medicina Clinica e Sperimentale, University of Pisa
}

\begin{abstract}
Jealousy is exclusively a human phenomenon because nonhuman animals lack the brain structures regulating the higher processes underlying jealousy.
\end{abstract}

Donatella Marazziti is professor of Psychiatry at the University of Pisa, Italy. Her main contributions are in the field of biological and clinical psychiatry, psychopharmacology, and human emotions. She was awarded several prizes, and she is in the editorial board of different journals. Her activity is documented by hundreds of publications. Website

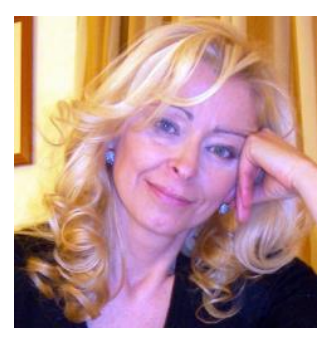

Cook et al. (2018) raise the question of whether jealousy exists in domestic dogs. They use a scale to assess dogs' aggressiveness using noninvasive functional magnetic resonance to measure the activity in the amygdala as one of the brain areas possibly involved. The results showed that most aggressive dogs had pronounced amygdala activation when watching their caregivers give food to a fake dog. The authors concluded that this might be indicative of a state that might resemble human jealousy.

The major flaw of the study is that no information is given on the breeds of the dogs examined: dogs' aggressiveness varies greatly by breed. The conclusions are also poorly grounded, being greatly influenced by our tendency toward anthropomorphism: attributing some of our own traits to animals.

Although people are often convinced that their companion animals (including cats, dogs, birds and horses) "feel" jealousy under specific circumstances and may show jealousy-like behaviors, it should be recalled that jealousy is a complex phenomenon that may be either a sensation or an emotion, or both. Jealousy can be defined as "a perception of a threat of loss of a valued relationship to a real or imagined rival" which includes affective, cognitive and behavioral components (Mullen 1991). Its peculiar function is to signal that the sexual partner is potentially desirable and attractive, can betray the other, and that strangers can jeopardize the stability of the couple. Obviously, jealousy can also be present in other cases, such as between family members, friends and coworkers. There is broad agreement that jealousy is a heterogeneous condition ranging from normality to pathology, with different degrees of intensity and persistence, involving different degrees of insight, and that even normal jealousy is quite variable and sophisticated, perhaps depending on individual differences in temperament.

It is a common experience that jealousy can occur acutely, resembling a panic attack. It is a primary emotion, like anxiety and fear, which are observed in dogs and are regulated by the 
amygdala and related limbic structures. In other cases, jealousy may be more devious and lead to a variety of psychiatric conditions, from depression to obsessive-compulsive disorder to psychosis, the "Othello Syndrome" (Todd 1955). In the most severe instances, it may lead to extremely aggressive self- and outward-directed acts of vengeance.

In any case, like all other human feelings and emotions, jealousy requires a series of cognitive processes that are probably lacking in animals including: the recognition of the importance of the relationship, the appraisal of the partner, the evaluation of the threats to the relationship, and catastrophic predictions of future scenarios without the partner. These highlevel processes are subserved by a series of brain structures that are present only in humans, but also by others that we share with animals and are devoted to the regulation of aggressiveness and attachment.

It does not seem too anthropocentric to conclude that jealousy is a typically human phenomenon because only human beings possess a brain that permits both its expression and, more important, the hallmark of a feeling: the awareness of it.

\section{References}

Cook P, Prichard A, Spivak M, \& Berns GS. (2018) Jealousy in dogs? Evidence from brain imaging. Animal Sentience 22(1)

Marazziti D, Di Nasso E, Masala I, Baroni S, Abelli M, Mengali F, Mungai F, \& Rucci P. (2003) Normal and obsessional jealousy: A study of a population of young adults. European Psychiatry 18(3):106-111

Marazziti D, Poletti M, Dell'Osso L, Baroni S, \& Bonuccelli U. (2013) Prefrontal cortex, dopamine, and jealousy endophenotype. CNS Spectrums 18(1):6-14

Marazziti D, Sbrana A, Rucci P, Cherici L, Mungai F, Gonnelli C, Massimetti E, Raimondi F, Doria MR, Spagnolli S, Ravani L, Consoli G, \& Catena Dell Osso M. (2010) Heterogeneity of the jealousy phenomenon in the general population: An Italian study. CNS Spectrums 15(1):1924

Mullen PE. (1991) Jealousy: The pathology of passion. British Journal of Psychiatry 158:593-601

Todd, J., \& Dewhurst, K. (1955). The Othello syndrome: A study in the psychopathology of sexual jealousy. Journal of Nervous and Mental Disease 122(4):367-374 